\title{
Protection of the Rights and Interests of Consumers in WeChat Shopping Disputes
}

\author{
Jin $\mathrm{He}$ \\ Wuhan University of science and technology \\ Wuhan, China
}

\author{
Yongwei Li \\ Wuhan University of science and technology \\ Wuhan, China
}

\begin{abstract}
In the Internet Plus era, with the increase of WeChat shopping, the disputes also increase. Because the access threshold of "microboss" is lower than that of the traditional online shopping, once consumption disputes occur, other person involved avoid responsibility through deleting friend or replacing account. Consumers are beset with difficulties. Therefore, the government should have sound market supervision and provide service to safeguard legal rights of consumers and maintain the healthy development of market according to law. Meanwhile, it is necessary to discuss whether it is applicable to use Law on Protection of the Rights and Interests of Consumers or use what kind of law and how to use applicable law to resolve disputes of WeChat shopping.
\end{abstract}

Keywords-WeChat shopping; consumption dispute; rights and interests of consumers

\section{INTRODUCTION}

Nowadays, WeChat has broken through the initial function as social platform and evolve into a popular platform for shopping. When you open WeChat Moments, the information of goods bought on somebody's behalf instead of the life and fresh news of friends is in the majority. The Moments become business circle. The WeChat shopping bases on social relations like Moments and WeChat group. The payment is prior to delivery. The buyer and the seller deal directly without a third party as guarantee. When the goods in "Moments" emerge in endlessly and the shops on WeChat prevail, the specialty of WeChat shopping makes consumers get into an awkward position in safeguarding legal rights.

\section{INTRODUCTION TO WECHAT SHOPPING}

\section{A. Origin of Wechat Shopping}

WeChat is a free application program providing instant messaging for intelligent terminals. It has functions of public platform, Moments and notification. Users can add friends and pay attention to public platform through "search number" and scanning QR code. The number of registered users breaks through 600 million by November 2013. It becomes the instant messaging software with the most users in Asian area. Nowadays, WeChat has become a powerful product with integration of social contact, electronic commerce, payment and $\mathrm{O} 2 \mathrm{O}$.

WeChat shopping means commodity transaction on WeChat platform. It is a business pattern occurring with social development. However, "WeChat shopping" doesn't appear overnight with the boom of WeChat Moments. E-commerce (namely electronic commerce) lays foundation for it like Taobao, QQ group, QQ zone and Weibo. The consumption concept and pattern of people keep pace with the times. With the emergence of WeChat payment in 2013 and the popularization of smartphone, an increasingly number of people does business in WeChat Moments. The WeChat shopping prevails correspondingly. Sellers using WeChat to transact commodities are called microboss, referring to a new type e-commerce group in nature.

\section{B. Classification of Wechat Shopping}

WeChat shopping is distinctly different from selling goods in Moments. According to different transaction main body especially the seller, it has two patterns: the first type is B2C microboss based on WeChat Official Account; the second type is $\mathrm{C} 2 \mathrm{C}$ microboss opening store in Moments [1]. The former means the suppliers of goods (including manufacturer, supplier and brand owner) directly face consumers through unified mobile store built on WeChat, responsible for management, delivery and after-sales service of products; the latter means the microboss personally shares, recommends and displays goods in the Moments. It can be divided into the following three types in detail:

1) Shopping in Moments: Speaking of WeChat shopping, most people think of WeChat friends advertising in Moments immediately. These friends upload pictures and information of products through Moments every day. This is the most common and active WeChat shopping. The survival and development of microboss in it base on the WeChat Moments. Buyers and sellers may be friends or acquaintances in real life. They transact online through the platform of WeChat. However, there are also operators with legal qualification transact through WeChat Moments.

2) Shopping in WeChat group: Except for Moments, some WeChat users spontaneously build WeChat group to carry out shopping through social relationship. For example, some "mothers" build shopping groups relevant to mother and baby products. Some will recommend reliable "purchasing agents" and invite them in the group to transact.

3) Transaction in micro shop: Transaction in micro shop refers to the official account transaction through WeChat identification. It is a shopping mode authorized by WeChat officials. It is similar to the traditional online shopping, 
referring to the transaction on micro shops achieving qualification on the third transaction platform and the transaction through WeChat Official Account. For example, on the Jingdong WeChat online shopping platform launched by WeChat and Jingdong, the suppliers of goods are merchants certified on the JD website, providing goods or service on WeChat. Some popularize and market goods or services through registering WeChat Official Account. It helps shopkeepers to open shop, put goods on sale, sell goods and safeguard legal rights. But these merchants need certification on WeChat platform. At present, the subject of small shop on WeChat can only be company instead of individuals.

\section{SHOPPING DisPUTES ON WECHAT AND DILEMMA IN SOLUTION}

\section{A. Expression of Shopping Disputes on Wechat}

1) Expression forms of shopping disputes on WeChat: Consumption disputes of WeChat shopping become new hot spot and characteristics of current consumption trend. The sellers fail to deliver goods after consumers pay through WeChat or consumers cannot find the seller when quality problems exist after receiving goods. Consumers don't know how to safeguard legal rights. After the rights and interests are damaged through WeChat shopping, consumers complain to industry and commerce department. The prominent problem is that the real information of the seller is unclear and consumers fail to provide corresponding consumption evidence. Industry and commerce departments cannot handle. Consumers' lawful rights and interests cannot be protected.

In short, the problems of shopping in "Moments" include: First, the quality of products cannot be guaranteed and consumers cannot depend on operators' self-discipline; second, consumers fail to distinguish products with crooked promotion; third, invoices are not provided in the transaction so consumers fail to prove the existence of transaction behavior; fourth, if the negotiation fails, operators blacklist consumers so others cannot find them; fifth, if products have quality problems, consumers fail to enjoy after-sales service.

2) Lawful rights and interests of consumers damaged: In WeChat shopping, consumers cannot enjoy the right of fair trade, the right to be informed, the right of safe transaction and the right of claim [4]. First, it lacks sales contract or the contract is nonstandard. For example, microboss displays the etext of contract prepared beforehand. Many articles are favorable to microboss. Consumers cannot but accept passively. Second, it is difficult for consumers to change or refund if they are dissatisfied with the goods. The WeChat shopping platform lacks the third party guarantee. The buyer and the seller transact directly. The initiative of changing or refunding is under the control of microboss. Third, the information of the buyer and the seller is asymmetric. Microboss may provide false information of goods or replace packaging of products and use price fraud deliberately. They raise prices of goods on purpose and consumers will step into the "trap" of price. Last, because WeChat shopping bases on the network and has strong openness, when microboss with bad intentions reveals consumers' real information, their right of transaction safety, personal safety and property safety will be threatened. Besides, when consumers buy dissatisfactory products with inaccurate measurement, virtual-high price and low quality on WeChat, they shall have the right to claim for compensation. But it is difficult to determine the information of microboss, so they often avoid the liability to pay compensation and consumers' right of claim cannot be guaranteed. Although the merchants are found, it is difficult to determine the applicable articles of law and competent court.

\section{B. Dilemma to Settle Shopping Disputes on Wechat}

1) The basis of relevant laws and regulations is unclear: The lawful rights and interest of consumers will be inevitably damaged in shopping disputes on WeChat. However, at present, the property of WeChat marketing and adjustment model is not defined clearly in law. Supervision and safeguard of legal rights have no legal basis. It is unclear that whether the Law on Protection of the Rights and Interests of Consumers is applicable to operation of microboss. Article II of Law of the People's Republic of China on Protection of Consumers' Rights and Interests stipulates the rights and interests of consumers are protected by this law in purchasing and using products or accepting service for living consumption; Article III stipulates operators shall abide by this law in providing products manufactured and sold by them or services for consumers. The Law on Protection of the Rights and Interests of Consumers neither bring WeChat shopping in the adjustment category nor exclude it from the adjustment category. Some people observe most microboss doesn't have certificate or license and cannot serve as market subject. They don't belong to "operators" prescribed in the Law on Protection of the Rights and Interests of Consumers. Industrial and Commercial Bureau of Gansu Province once issued, "WeChat shopping belongs to private transaction of individuals different from online shopping and it is not protected by this law". [5] Naturally, it doesn't belong to the regulatory scope "sales return is feasible if consumers are dissatisfied with goods after receipt".

2) It is difficult to define the subject of liability: WeChat shopping is proceeded on the mobile phones and the network. Merchants will deliver the goods after consumers pay money to WeChat wallet or bank account of them. It is different from traditional shopping on the limited real information. When consumers shop in physical stores, they can check business license and goods with low crisis and clear subject of liability. Individuals only need to register a WeChat account to sell products or services through WeChat. The shops can open without the real name of operators and relevant certificates. Consumers fail to know the real information of the seller, provide corresponding consumption evidence and check the place of origin and manufacturing enterprise of products. When consumption disputes occur, the seller can directly delete friends or replace account to avoid the responsibility. The definition of subject of liability becomes the biggest dilemma faced by consumers in safeguard of legal rights. Furthermore, microboss don't provide receipt voucher so consumers don't have important evidence. The evidence is hard to obtain even by the court and the legal aid is limited. The cost in safeguarding legal rights is high. 
3) Difficult to determine the court within jurisdiction in lawsuit: Legal way is the last resort of consumers of WeChat shopping in safeguard of legal rights, but it is difficult to determine the court within jurisdiction. On one hand, microboss will not let others know their real identity or address It is difficult to investigate information of merchants like real address so the competent court of its home location cannot be determined. On the other hand, the place of performance of WeChat shopping contract is unclear. According to the Contract Law, the place of performance of sales contract shall be clear. If the buyer picks up goods voluntarily, the place of performance is at the place of picking up goods; if the seller provides home delivery service, the place of performance is at the place of reception. However, it is difficult to determine the place of performance of WeChat shopping contract.

\section{MeAsures to SETtLE WeChat Shopping Disputes}

\section{A. Opinions on Current Laws Applicable to Wechat Shopping Disputes}

At present, the applicable laws for WeChat shopping disputes are still controversial like the Law on Protection of the Rights and Interests of Consumers, Contract Law and general rule of civil law. The authors address we should differentiate the trading forms on WeChat since no explicit stipulation exists in laws at present. First, it is the transaction through private letter. It belongs to private deal not applicable to Law on Protection of the Rights and Interests of Consumers but applicable to Contract Law and general rule of civil law. Second, it includes the behaviors marketing products through Official Accounts or marketing behavior in transaction applicable to Law on Protection of the Rights and Interests of Consumers. Third, the market subjects with legal qualification transact through WeChat. It is applicable to Law on Protection of the Rights and Interests of Consumers. Fourth, it is the transaction in micro shops with legal qualification namely the third party transaction platform, applicable to Law on Protection of the Rights and Interests of Consumers.

\section{B. Measures to Improve the Protection of the Rights and Interests of Consumers Involved in Wechat Shopping}

1) Subjects of each party clarify responsibilities and strengthen joint defense to prevent the frequent occurrence of WeChat shopping disputes: WeChat shopping is not a no man's land beyond our management. It is imperative to build a comprehensive linked network for supervision and prevention. Administrative departments should cooperate with WeChat officials to build a normative and professional registration system for microboss. When the interests are damaged in WeChat shopping, consumers can safeguard their legal rights according to law. Meanwhile, WeChat officials can build margin system and real-name registration system, requiring operators to register with real name and pay cash deposit. Before consumption on WeChat platform, consumers can inquire basic information and credit status of operators, the location of shops, and the qualification of microboss through registration platform.

2) Accelerate legislative process and clarify applicable laws to protect lawful rights and interests of consumers: At present, the legislation of WeChat shopping is backward, so that the behaviors infringing the rights and interests of consumers cannot be effectively governed. The existing laws and regulations cannot protect the rights and interests of consumers in WeChat shopping. [6] In the Internet Plus era, as a burgeoning marketing pattern, WeChat marketing has attracted many operators and consumers. Legislative branches should accelerate the legislation process in WeChat shopping. All transaction behaviors in WeChat shopping should be included in the regulatory scope of laws to effectively supervise microboss. With the soaring development of microboss, form legal system with WeChat platform as supervision object and establish sound legal system of WeChat shopping according to different characteristics of online shopping platforms to bring WeChat shopping platform in the protection scope of laws and regulations and protect the lawful rights and interests of consumers. Moreover, online law enforcement agencies and professional online law enforcement teams should be established to supervise the transaction process and punish unscrupulous merchants.

3) Establish mechanism to settle disputes and intensify punishments and apply rules of mediation and arbitration: Most products in the transaction are in small amount in WeChat shopping. When disputes occur, many consumers will give up the safeguard of legal rights because of the high lawsuit cost and difficulties. Relevant departments shall establish mediation and arbitration systems favorable to consumers to settle the disputes and protect the rights and interest of consumers. For example, network platforms can be established for buyers and sellers to solve problems through timely negotiation. Scientific rules of jurisdiction of the court should be established for consumers to prosecute rapidly. Punishments for unscrupulous merchants can be intensified. Criminal punishment can be applied to microboss with fraudulent conducts with large amount and wicked circumstances; relevant authorities can register and investigate when the circumstances are particularly serious.

\section{CONCLUSION}

In conclusion, the authors address it is a narrow and unfair attitude to exclude the safeguard of legal rights in WeChat shopping from the Law on Protection of the Rights and Interests of Consumers. In the big data era, online consumption has had earthshaking influence on people's life. Consumers should be rational and cautious to shop on WeChat, asking the seller to provide inspection report before transaction and invoice or receipt in delivery and keeping the contact information and real name of the seller. Chatting records and valid evidence should be kept for protection of rights. If the products have quality problems, consumers need to consult with the seller timely. If negotiation fails, consumers can complain to China Consumers Association or relevant administrative departments, or appeal to the court.

\section{REFERENCES}

[1] Zhang Junlun. Microboss of Enterprises [J], Modern Enterprise Culture, 2016(34) 
[2] Xia Yonggen. Why Enterprises Market on WeChat? Reasons Are Here [J], Northern Animal Husbandry, 2014 (24): 32-32

[3] Xiao Xinxin. Impact and Thinking of Media Attribute of WeChat on Authenticity of Public Information [J], Journalism and Communication, 2014(4)

[4] Wang Jun. How to Protect the Rights and Interests of Consumers WeChat Shopping [J], People's Tribune, 2016(25)

[5] Deng Xueping. Whether the Law on Protection of the Rights and Interests of Consumers Is Applicable to Disputes of WeChat Shopping [J], Public Management Research, 2016(3): 40-41

[6] Du Jingyan. Protection of Consumers WeChat Shopping [J], Chutian Fazhi, 2015(9). 